\title{
Crigler-Najjar Syndrome: A Rare Fatality
}

Alizah Alaman, Munira Minaz Ali, Nazish Hussain Ali Pachani \& Anmol Minaz Ali

Agha khan University Hospital, Nursing Department

Corresponding Author: alizah.alaman@gmail.com

\section{Abstract}

This paper reviews Crigler-Najjar Syndrome as a rare fatality affecting individuals in the early years of life. It's rare incidence, mis-diagnosis and severe complications resulting in death at the early age has cause difficulty in determining its exact frequency in general population. This syndrome, is described by the accumulation of un-conjugated bilirubin in the body due to the inheritance of defects UGT1A1 genes. This anomaly disrupts the bilirubin mechanism at a greater extent. The high level of bilirubin in the body manifests itself in terms of specific signs and symptoms among which jaundice is most common and well-known. Therefore, treatment is primarily directed towards decreasing accumulation of un-conjugated bilirubin in the body. Aspects of liver transplant can be seen as permanent treatment plan at risk to benefit ratio.

Keywords

Crigler-Najjar Syndrome, genetic inheritance, genes, bilirubin, metabolism, Hemolysis, jaundice, kernictus

\section{Introduction}

Cells are building blocks of all living organisms. Its anatomical structure and physiological activity is best suited for its evolutionary changes among generations. These cells have a peculiar property which makes an individual extraordinarily unique. These blueprints of life are the genes that are required to maintain integrity of life. However, when a slightest of change occurs in their structure a specific sequence of nucleotides, mutation is likely to take place. These genetic mutations are as diverse as genes itself, ranges from causing mild problems to be immoderate and even to cause death. One such type is Crigler-Najjar syndrome that has been a rare but highly inimical for human beings. This paper, at paramount will attempt to unravel the magnitude of this disease nationally and globally. Furthermore, it attempts to discuss the encountered case scenario, causes, risk factors, nursing care and recommendations regarding Crigler-Najjar syndrome.

\section{Description of Crigler-Najjar Syndrome}

Crigler-Najjar syndrome (CNS) is an uncommon genetic disorder that affects the metabolism of bilirubin produced by the Hemolysis of RBCs. The disorder causes the accumulation of unconjugated bilirubin in the body, causing non-hemolytic jaundice. This unconjugated bilirubin causes brain damage in infants called kernicterus. The inheritance pattern of Crigler-Najjar syndrome is autosomal recessive inheritance (Rimoin, Connor, Pyeritz\&Korf 2002).

It has been classified into 2 types CNS I and CNS II. Crigler-Najjar syndrome I is the most severe of its types and patient's rarely survived till adulthood. A research has been conducted in Tunisia in 2010, 30 cases of CNS I was recruited for the study, but due to severity of disease and kernicterus, 28 cases died during the research period (Aloulou, Ben, Khanfir, Ben andChabchoub, 2010). In CNS I the serum bilirubin levels are usually above $345 \mu \mathrm{mol} / \mathrm{L}$ (range 310-755 $\mu \mathrm{mol} / \mathrm{L}$ ). CNS II is a less fatal condition in which bilirubin levels are below $345 \mu \mathrm{mol} / \mathrm{L}$ (range $100-430 \mu \mathrm{mol} / \mathrm{L})$. Some cases of CNS II are 
also detected later in childhood. Due to low serum bilirubin levels, kernicterus occurs rarely in type II (Burt, Portmann, Ferrell, \&MacSween, 2012). Thus, Crigler-Najjar syndrome type I can be defined as complete lack of enzymatic activity and results in severe symptoms whereas in Crigler-Najjar syndrome type II there is partial enzymatic activity results in milder symptoms.

\section{History and Frequency}

CriglerNajjar syndrome was primarily identified in six newborns of three families who were blood relatives (consanguineous). These cases were also described in the medical literature in 1952 by Drs.Crigler and Najjar. In 1962, Dr. Arias reported less severe version of this disorder, which is now termed Crigler-Najjar syndrome type II.
The frequency of Crigler-Najjar syndrome is estimated to be 1 child out of 1 million newborns worldwide (Askari, 2006). According to its statistical data, this disease affects both gender populations equally. In the general population, the incidence is approximated to be 1 in 750,000-1,000,000 people. Many researchers believe that this disease often gets misdiagnosed and its rare nature makes it intricate to know its exact frequency in the general population.

\section{Recessive Genetic Disorder and its Occurrence}

The recessive genetic disorders arise when an individual inherits the anomalous gene for the identical trait from each parent (Rimoin, Connor, Pyeritz \& Korf, 2002).

(Fig 1)

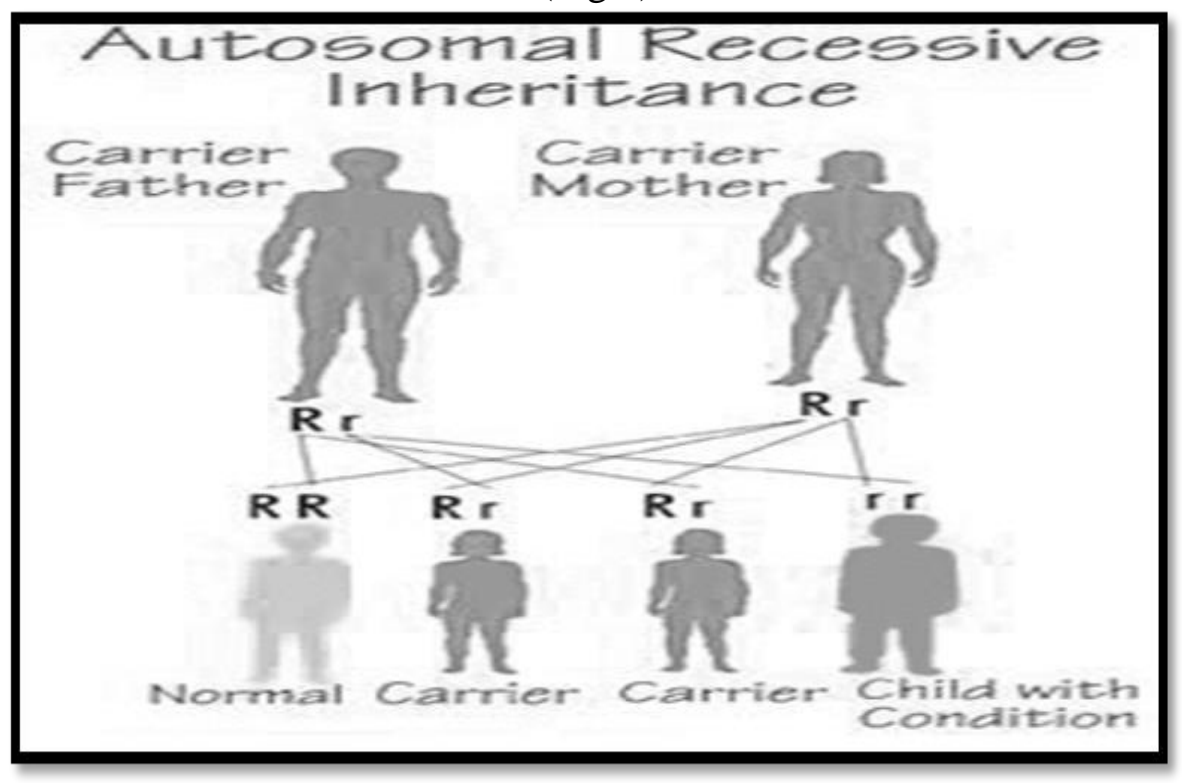

If both the parents are carrier for the disease, so the risk for passing the anomalous gene and have an affected child with CNS is $25 \%$ with each pregnancy. The risk for getting the carrier child is $50 \%$ and a normal child with healthy genes is $25 \%$ (Fig 1).

Similarly, if a person with a disease marry with a carrier mate have the defected UGT1A1 gene, so there will be a chance to have $50 \%$ affected child with each pregnancy and $50 \%$ carrier child (Figure 2). 
(Fig 2)

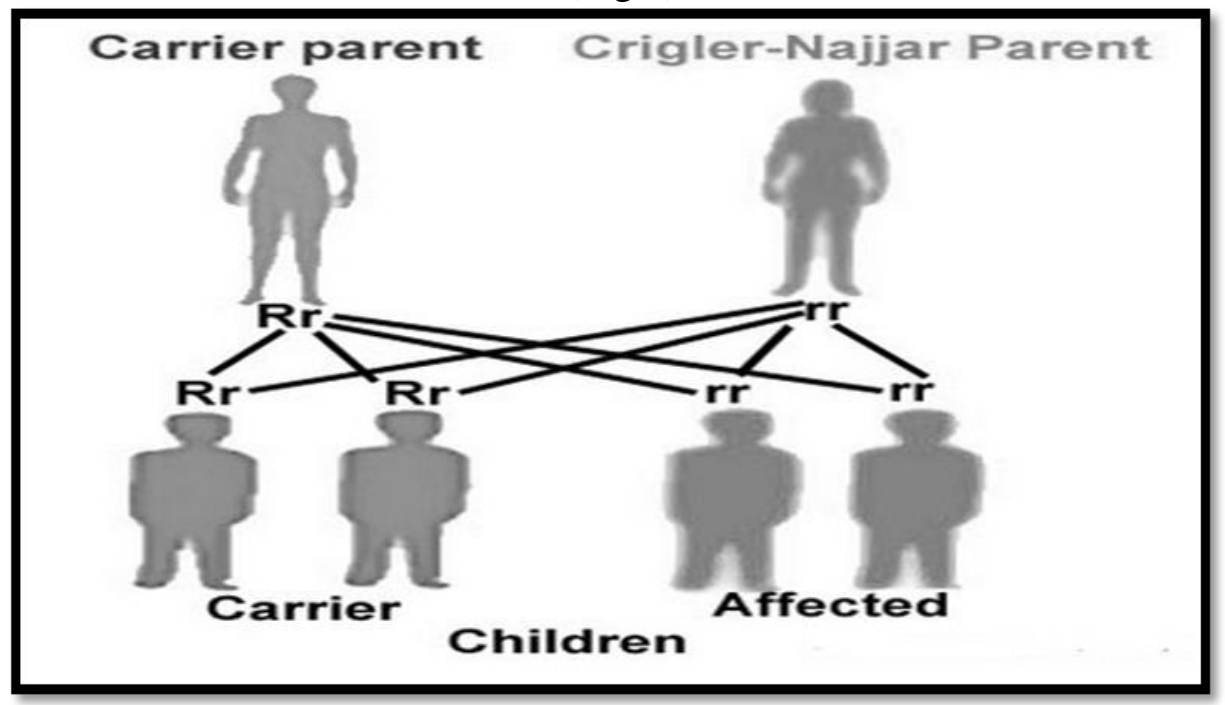

\section{Case Scenario:}

In a secondary care hospital in Pakistan, a 9month old baby was admitted with complain of severe Jaundice and altered mental status since 5 days. During assessment, the patient appeared lethargic and younger from his prescribed biological age. The history revealed that the boy had a history of intermittent jaundice episodes for nine months. He was a full term infant with a birth weight of $3500 \mathrm{~g}$. His parent's had consanguineous marriage 3 years before. During the initial days of his life, he suffered from jaundice with no other comorbids. Biochemical studies revealed severe unconjugated hyperbilirubinemia i.e. $56 \mu \mathrm{mol} / \mathrm{L}$. Consequently, the child received phototherapy treatment for seven days and jaundice subsided. However, intermittent onset of jaundice occurred during 9 months and the child was frequently hospitalized. The child appeared very fussy, not able to breastfeed properly, with low urine output, poor sleep, his skin was very pale with yellowing of mucous membrane and sclera of eyes. Liver Function Tests showed insignificant results, abdominal ultrasound revealed no liver anomaly, bile analysis demonstrated absence of bilirubin glucuronides and urine analysis showed undetectable bilirubin. The father was healthy, but his mother was presented with slight jaundice. After comprehensive clinical and laboratory findings, the doctors decided to have genetic investigation for CriglerNajjar Syndrome. Till that time the child was kept under intense phototherapy, Phenobarbitals were continued and doctors planned for plasmapherersis thrice a week.

\section{Pathological Basis of Crigler-Najjar Syndrome:}

In order to understand the pathology of Crigler-Najjar Syndrome, It is necessary to discuss the normal mechanism of bilirubin excretion. According to Burt, Portmann, Ferrell, \& Mac Sween (2012) Bilirubin is an orange-yellow compound that is released as a byproduct of breakdown of RBCs known as Hemolysis. Bilirubin binds with albumin (unconjugated bilirubin) that is insoluble in water circulates to the liver to get conjugated. To get excreted from the body, the unconjugated bilirubin needs to get conjugated (soluble in body fluids). In Liver Bilirubin-UGT enzyme converts unconjugated bilirubin to conjugated bilirubin. The conjugated bilirubin then 
excreted in the bile and during digestion process the bile mixes with urine and feces and eliminate out from the body.

In Crigler-Najjar syndrome, the unconjugated bilirubin is not converted to conjugated bilirubin and thus accumulates in the blood causing jaundice and other complications. The most severe complication of accumulated unconjugated bilirubin is bilirubin encephalopathy known as kernicterus.

\section{Genetic Changes Leading to Crigler-Najjar Syndrome:}

Chromosomes present in human cell nucleus carry genetic makeup of an individual. In accordance with Arias, Gartner and Cohen (1969) Crigler-Najjar syndrome usually results by mutations caused in UGT1A1 gene situated on the long arm (q) of chromosome 2 (2q37). The UGT1A1 gene encompasses information for encoding a liver enzyme known as uridine disphosphateglucuronosyltransferase (UDPGT). The enzyme is very essential for the bilirubin conjugation and its excretion from the human body.

Researchers have proposed, the fact that mutations in the UGT1A1 gene disrupts the normal conjugation mechanism of bilirubin and thus causes Crigler-Najjar syndrome. The gene provides the instruction for producing an enzyme known as uridine diphosphate glucuronosyl transferase (bilirubin-UGT) enzyme which is found in liver cells. The bilirubin-UGT enzyme performs a metabolic reaction refers as glucuronidation. In this reaction, the enzyme transfers glucuronic acid to unconjugated bilirubin and its combination produces conjugated bilirubin.

(Fig 3)

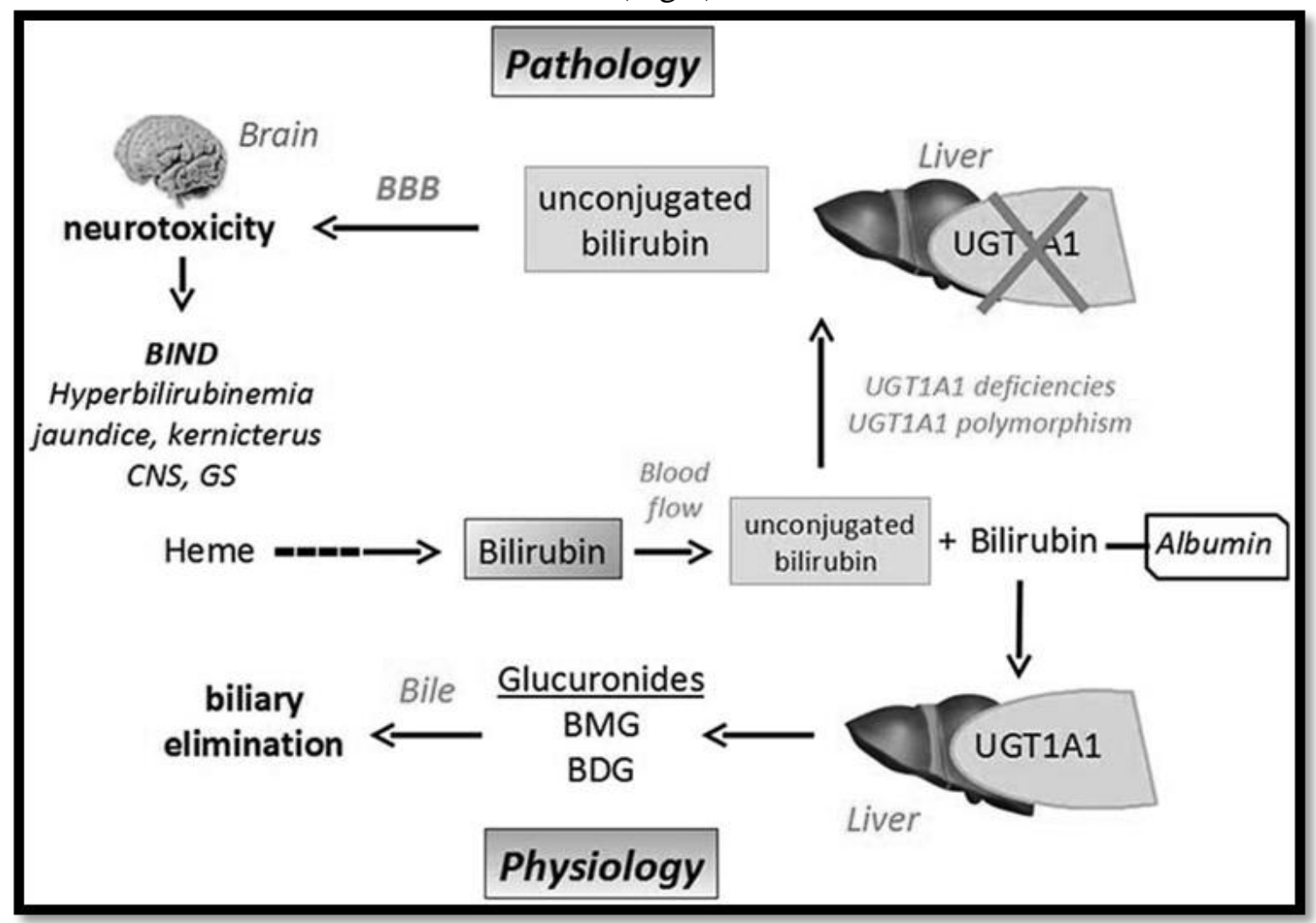


The above (figure 3) shows the pathology of the disease evidently. The mutation in UGT1A1 gene results in absent or minimal function of bilirubin-UGT enzyme. The altered level of this enzyme resists the conjugation process. The toxic unconjugated bilirubin accumulates in the blood causing unconjugated hyperbilirubinemia and jaundice. People with CNS I have no enzymatic activity while people with CNS II have not as much of than $20 \%$ of the normal function (Askari, 2006).

Referring to the above scenario, Genetic Investigation of that child showed mutation in the UGT1A1 gene with insufficient amount of uridine diphosphate glucuronosyl transferase (bilirubin-UGT) enzyme. The child was homozygous for the defective UGT1A1 gene. Parental testing was suggested, but due to poor financial background and low literacy, the father refused for further testing and emphasized to treat his child conservatively. Literature attenuated that parents of children suffering from CNS may demonstrate some alterations in bilirubin metabolism, however, they do not exhibits any bodily findings of this disorder as they are heterozygous for the anomolous UDPGT gene (Behrman, Kliegman, Jenson, 2005).

\section{Signs and Symptoms}

The clinical manifestations varied slightly for both, type I and type II. In type I disorder, symptoms appear soon after birth and persist for at least three weeks after birth. Infants with type I disorder develop severe jaundice, which is evident by yellowing of skin, mucous membrane and whites of eyes. Similar symptoms were noted in the aforementioned case. The child also had jaundice, which was intermittent for 8 months. According to National Organization for Rare Disorder (2008) due to severe jaundice, affected infants are at high risk for developing kernicterus at the first month of life. Kernicterus is life threatening condition in which high level of bilirubin accumulates in the brain and damage central nervous system. Memon, Weinberger, Hegyi, \&Aleksunes (2015) elucidated that early symptoms of kernicterus include fever, vomiting, lethargy and unsatisfactory breast feeding. Moreover, the child looks very fussy and do not have enough wet or dirty diapers. Likewise, very similar symptoms were noted in the above case like low urine output, lethargy, and unsatisfactory breast feed. Later on, infant may be manifested by hypotonia, high pitched cry, severe muscle spasm and diminished or absent reflexes such as mororeflex, sucking and rooting reflexes. Furthermore, kernicterus can also result in hearing loss, convulsions, involuntary muscle movement, brain damage and ultimately death (Memon, Weinberger, Hegyi, \&Aleksunes, 2015). Likewise, the child in the above case had similar clinical manifestation such as weakness, lethargy, high pitched cry, unable to suck and breast feed.

Crigler-Najjar Syndrome Type II is milder disorder than type I. In type II, jaundice may occur in infancy or later in life. Jaundice may be discernible until precipitated by certain conditions such as infection, prolonged fasting or certain drug usage. Kernicterus is rarely associated with type II disorder. However, in some cases it may occur if affected individual has sepsis, prolong fasting, taking certain medications or under general anesthesia (National Organization for Rare Disorder, 2008).

\section{Treatment}

The treatment of the Criggler-Najjar syndrome is aimed to reduce the unconjugated bilirubin level in the blood. Early detection and treatment is crucial in type I to prevent Kernicterus during infancy life. Lucey and Suresh (2002)explicatedthatthe 
first line of treatment for CriglerNajjar syndrome includes intensive phototherapy to excrete bilirubin level in the skin and to speed up its decomposition. Phototherapy is helpful during early stage of life; however, with increasing age phototherapy becomes less effective in reducing bilirubin level. Thus, it remains unsuccessful in preventing Kernicterus. Besides, plasmapherersis has been used as another treatment modality for Crigler-Najjar Syndrome type I.Plasmapherersis is a therapeutic modality to remove toxic substances and plasma parts from the blood. Thus, it helps to remove toxic bilirubin from the blood. During this procedure, blood is removed from an individual's body and the plasma is separated from blood cells. Then, the plasma is replaced by other human plasma and patient is transfused with blood (Lucey and Suresh, 2002).

Since, the chance of neurological involvement is high in type I, liver transplant is considered as the only permanent treatment option for type I disorder in order to provide the body with enzyme UGT1. Liver transplant is a recommended option for the infants with severely elevated level of unconjugated bilirubin and who do not respond to other therapies. Liver transplant is also suggested by physicians as a preventive therapy to prevent the development of Kernicterus that can result in brain damage and death. However, there is always a risk to benefit ratio behind every modality. A possible complication of liver transplant such as rejection of transplanted organs, hepatic artery bleeding and thrombosis, and sepsis cannot be unseen. Transplanted patients have to take lifetime immunosuppressant, intermittent blood testing and physician checkups becomes compulsory in such patients (National Organization for Rare Disorder, 2008).
Crigler-Najjar syndrome type II is a mild disorder, therefore, Phenobarbitals are considered effective for type II disorder. It rapidly decreases the plasma bilirubin level in affected individuals (Labrune, 2004). Moreover, children with type II may need phototherapy during the period of hyperbilirubinemia. Many children with type II may not need any treatment and only require vigilant observation (National Organization for Rare Disorder, 2008).

Some investigational therapies have been used to decrease bilirubin production via the use of inhibitors. Such as tin-protoporphyrin and Tin mesoporphyrin which have been used to lessen the production of bilirubin by inhibiting enzyme heme oxygenase. Heme oxygenase is an enzyme which catalyzes the catabolism of heme to bile pigment. However, more research is needed to inspect long term efficiency and side effects of such inhibitors (Lucey \& Suresh, 2002).

According to Lucey and Suresh (2002), a research had been conducted in which a 10year-old girl diagnosed with Criglernajjar syndrome type I was treated with hepatocytes transplantation. In this procedure donor's liver cells were transfused and patient was monitored hemodynamically. After procedure, patient's UGT activity was 5.5\% of the normal and after eleven months of procedure, UGT level was $14 \mathrm{mg} / \mathrm{dl}$. Moreover, her requirement for phototherapy also decreases from 10-12 hours per day to 67 hours per day. Thus hepatocytes transplantation proved to be helpful in managing the disease.

\section{Nursing Care with Model}

As nursing students, we encountered this case in one of our clinical placement in a secondary care hospital in Pakistan. Initially, we took a detailed history from parents and covered all the aspects of functional health 
pattern. This time period was very traumatic for the patient, for his family and for hisfriends. There was a list of stressors around. Frequent hospitalization was a solemn burden for the family. The mother was found to be in guilt of being a diseased parent. As a forefront health care provider, we tried at best to provide as much comfort as possible. We integrated the conceptual model of famous theorist named Dr. Katharine Kolcaba. She presented a Comfort Theory of Nursing in 1999 (Refer to the figure No. 04.

(Fig. 4)

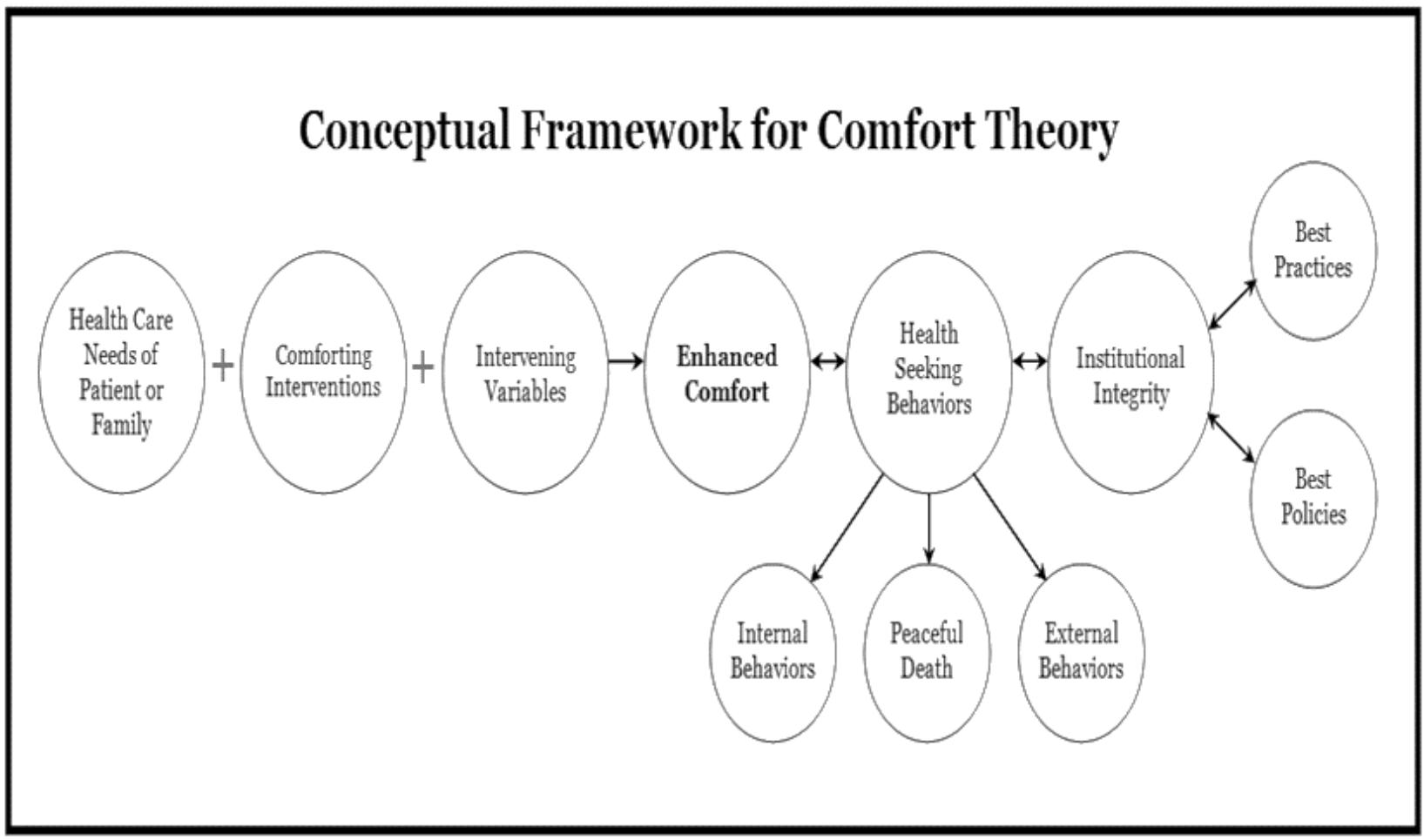

She highlighted that the core function of Nursing practice is to aid the patient and their family to attain a maximum level of comfort(Nursing-theory.org, 2016). To enhance the comfort level of the child, diverse play therapies was introduced. Rattle, Wing Chang and coloured cartoon pictures were introduced as to divert the client's mind from the suffering of pain. Moreover, the child had limited movement due to the disease process and its discomfort. In order to avoid contractures, frequent ROM was performed and parents were also taught about the technique. Huang and Ness (2011) explicated that exercise improves muscle strength and endorses the release of growth factors thus escalating skeletal growth in patients. Kangroo Mother Care was also taught to the mother as to enhance physical and psychosocial comfort of the child. In addition, the child had altered nutrition less than body requirement and he wasn't able to breastfeed properly. For this frequent short meals, and jellos were added to the diet.

Knowledge deficit about the disease condition, prognosis of illness and understanding of the possible treatment plan were the primary health care needs identified at the time of history taking. As a group of nursing students, we conducted a teaching session using an illustrative technique to 
provide a holistic information about out the disease condition, literature review about the prognosis, and risk benefit understanding of the treatment plan. This effort turns out very motivating because the teaching made parents self-reliant to ask relevant questions from the team of healthcare provider with sufficient information and then able to give consent for a better treatment plan. The beauty of this teaching was that it was conducted in the local language and patient family education reading material was also provided with sufficient pictures so that in our absence the content can be reviewed. This intervention really gave parents a power and inner relief from guilt and doubts. The parents were experiencing ease and they were demonstrating health seeking behavior to acquire positive outcomes. Moreover, we refer them to the financial counselor facility at the setting so that the finance department may help them throughout the course of disease. The family and friends support played a vital role in providing psychological support to them. The unconditional love and warmth of family readily ease the guilt of the mother.

\section{Research Needs}

Intense research is needed in the field of gene therapy in order to cure this metabolic disease. Moreover, biochemical studies of enzyme deficiency involved in congenital hyperbilirubinemia needs to be done in depth so that, alternative to liver transplant or other intense treatment can be developed in the form of synthetic or animal extracted enzymes. Besides, diagnostic methods should be developed in order to detect the metabolic disease in early stage of pregnancy in order to identify the disease earlier.

\section{Conclusion}

In conclusion, Crigler-Najjar syndrome is a rare and infrequent genetic disorder that remains a highly ruinous issue to one's life. Therefore, more research is needed in order to manage early symptoms and paramount importance is recommended in the field of genetics to help diagnose this in the fetal stage. Also, aspects of liver transplantation could be seen on risk to benefit ratio. To sum up, holistic care should be the foremost priority for health care providers in improving individual's health and eventually their quality of life.

\section{Foot note}

*These authors have contributed equally to the work.

\section{Conflict of Interest}

We do not have any Conflict of interest.

\section{Source of Funding}

Not required

\section{Ethical Clearance}

Not required

\section{References}

- Aloulou, H., Ben, T., Khanfir, S., Ben, M., \& Chabchoub, I. (2010). [Type I CriglerNajjar syndrome in Tunisia: a study of 30 cases]. - PubMed - NCBI. Ncbi.nlm.nih.gov. from http://www.ncbi.nlm.nih.gov/pubmed/20 890816

- Arias, M., Gartner, M., Cohen, M. (1969). Chronic nonhemolytic unconjugated Hyper bilirubinemia with glucuronosyltransferase deficiency. Am J Med. 47:395-409.

- Askari, K., (2006).Crigler-Najjar Syndrome. NORD Guide to Rare Disorders. Lippincott Williams \& Wilkins. Philadelphia, PA.

- Behrman, E., Kliegman, M., Jenson, B. (2005). Nelson Textbook of Pediatrics. 17th ed. Elsevier Saunders. Philadelphia, PA; 1320-1321.

- Burt, A., Portmann, B., Ferrell, L., \&MacSween, R. (2012). MacSween's 
pathology of the liver. Edinburgh: Churchill Livingstone/Elsevier.

- CriglerNajjar Syndrome - NORD (National Organization for Rare Disorders).(2008). NORD (National Organization for Rare Disorders). Retrieved 20 July 2016, from http://rarediseases.org/rarediseases/crigler-najjar-syndrome/

- Huang, T., \& Ness, K. (2011). Exercise Interventions in Children with Cancer: A Review. International Journal of Pediatrics, 2011, 1-11. doi:10.1155/2011/461512

- Labrune, P. (2004). Crigler-Najjar syndrome (1st ed., pp. 1-4). France: JeanMarie saudubray.

- Lucey, J. \& Suresh, G. (2002). Welcome to the Crigler-Najjar Syndrome Web Site. Retrieved 19 July 2016, from http://criglernajjar.altervista.org/oldcnsite .pdf

- Memon, N., Weinberger, B., Hegyi, T., \&Aleksunes, L. (2015). Inherited disorders of bilirubin clearance. Pediatr Res, 79(3), 378-386. http://dx.doi.org/10.1038/pr.2015.247

- Nursing-theory.org. (2016).Kolcaba's Theory of Comfort - Nursing Theory. Retrieved from

- http://www.nursing-theory.org/theoriesand-models/kolcaba-theoryofcomfort.php

- Rimoin, D., Connor JM, Pyeritz RP, Korf BR, (2002). Emory and Rimoin's Principles and

- Practice of Medical Genetics.4th ed. Churchill Livingstone. New York, NY; 1803-1818. 